Jorge Retamal Valenzuela*

Ministro Titular del Tercer Tribunal Ambiental

jorge.retamal.rv@3ta.cl

\title{
Coexistencia de facultades fiscalizadoras entre la Corporación Nacional Forestal y la Superintendencia del Medio Ambiente. Un caso de análisis ${ }^{* *}$
}

Coexistence of supervisory powers between the National Forest Corporation and the Environmental Protection Agency. A case of analysis

\section{Resumen}

El estudio muestra el conflicto existente entre facultades de la Corporación Nacional Forestal y la Superintendencia del Medio Ambiente, y busca determinar el sentido y alcance normativo para resolverla.

* Abogado, Magister en Derecho Ambiental. Ministro Titular Abogado del Ilustre Tercer Tribunal Ambiental. El presente trabajo nace de la tesis del autor para optar al grado académico de Magister en Derecho Ambiental por la Universidad de Chile, aprobada por la comisión evaluadora de la Escuela de Postgrado, de la Facultad de Derecho de la misma Universidad, con fecha 16 de enero de 2015.
Palabras clave

Antinomia - controversia jurídica - CONAF - SMA - non bis in idem.

\section{Abstract}

This study shows the conflict between powers of the National Forestry Corporation and the Superintendent of the Environment and seeks to determine the normatives meaning and scope to resolve it.

\footnotetext{
** Artículo recibido el 17 de Junio de 2015 y aceptado para su publicación el 9 de Julio de 2015
} 


\section{Key words}

Antinomy - legal controversy - CONAF - SMA - double jeopardy.

\section{Introducción}

El correcto funcionamiento de las instituciones del Estado depende fundamentalmente de la no interferencia de funciones entre ellas, especialmente cuando nuevos organismos se incorporan a este conjunto de instituciones, y comienzan a ejercer las facultades que el legislador les ha otorgado.

Cada vez que se crea un nuevo servicio o una nueva institución, se hace necesaria una acertada interpretación del ordenamiento jurídico acerca del alcance de sus competencias en relación con el resto de las reparticiones y servicios con los que se va a relacionar, con el fin de velar por que dichos organismos operen en forma ordenada, y no se provoquen interferencias en su actuar.

El presente artículo aborda el conflicto de facultades existente entre la Superintendencia de Medio Ambiente y la Corporación Nacional Forestal, a propósito de la aplicación del artículo 59 de la Ley Orgánica de la Superintendencia del Medio Ambiente ${ }^{1}$, que prohíbe, entre otras acciones, denunciar ante los Tribunales de Justicia los hechos respecto de los cuales la Superintendencia ya referida haya iniciado procedimientos sancionatorios. Esto, porque simultáneamente pesa sobre la Corporación Nacional Forestal una obligación legal, de denunciar a los Tribunales de Justicia los incumplimientos a las obligaciones forestales del D.L. 701 y la ley $\mathrm{N}^{\circ} 20.283$, sin distinguir la situación que ocurre cuando las normativas forestales que no se han cumplido -planes de manejo o cortas ilegales- forman parte de una Resolución de Calificación Ambiental, o de un Permiso Ambiental Sectorial que tengan relación con un proyecto determinado, o se sitúen dentro del territorio en donde se emplace este mismo proyecto. ${ }^{2}$

En la perspectiva de analizar las causas y, en segundo término, los diversos mecanismos por vía de los cuales la doctrina y la jurisprudencia han intentado soluciones cuando han surgido esta clase de controversias, el presente estudio comenzará contextualizando la discusión, abordando diversos aspectos referidos a la institucionalidad ambiental, la institucionalidad forestal, los conflictos de leyes, el principio de non bis in idem, el concepto de "bien jurídico" y algunos aspectos relativos a la separación de poderes del Estado y a la derogación de las leyes, que en conjunto constituirán el marco teórico del presente trabajo. Al final, se propondrá una solución del problema en cuestión, aplicando los elementos aportados por la doctrina y la jurisprudencia, a fin de plantear

Contenida en el artículo segundo de la ley $\mathrm{N}^{\circ}$ 20.417, publicada en el Diario Oficial con fecha 26 de Enero de 2010.

2 La problemática fue detectada por el autor mientras se desempeñó como Abogado analista de la Fiscalía de la Corporación Nacional Forestal, entre los años 2012 y 2013(Nota del autor). 
una nueva opinión que aporte al debate en torno a la creación por ley de nuevas instituciones y que, como con frecuencia ocurre, en su implementación presenta aspectos de incertidumbre e interpretación controversial.

\section{Exposición de la problemática jurídica}

Dentro de los proyectos que se someten al Sistema de Evaluación de Impacto Ambiental (en adelante, también "SEIA"), existen aquellos que, por considerar obras civiles, deben intervenir bosques, para lo cual deben obtener los permisos ambientales sectoriales (PAS) que otorga la Corporación Nacional Forestal (CONAF), y que se encuentran contenidos en los artículos 102 a 105 del Decreto Supremo N ${ }^{\circ} 95$ del Ministerio Secretaría General de la Presidencia, del año 2001, antiguo Reglamento del Sistema de Evaluación de Impacto Ambiental, y en los artículos 127, 128, 129, 148, 149, 150, 151 y 152 del Decreto Supremo N $N^{\circ} 40$ de 30 de Octubre de 2012, publicado en el Diario Oficial el 12 de Agosto de 2013, del Ministerio del Medio Ambiente, actual Reglamento del Sistema de Evaluación de Impacto Ambiental. En consecuencia, las intervenciones de bosque se encuentran reguladas y deben cumplir con las condiciones que se establecen por CONAF, conforme al Decreto Ley $\mathrm{N}^{\circ}$ 701, a la ley $\mathrm{N}^{\circ} 20.283$ y a sus respectivos reglamentos.

El problema tiene su origen en la existencia de facultades fiscalizadoras de CONAF y de la Superintendencia del Medio Ambiente, ambas otorgadas por ley. La pertinencia del uso de las mismas, su oportunidad y alcance ha generado interpretaciones dispares, incluso desde antes de la entrada en vigor de las facultades fiscalizadoras de la Superintendencia del Medio Ambiente. En los hechos, se verificó un intercambio de opiniones oficiales entre el Servicio de Evaluación Ambiental (SEA) y CONAF en dicha materia, mientras estuvieron vigentes las disposiciones transitorias pertinentes de las leyes $\mathrm{N}^{\circ} 20.417$ y $\mathrm{N}^{\circ} 20.600^{3}$.

La controversia respecto de las facultades fiscalizadoras subsiste hasta hoy, y se ha hecho explícita cuando CONAF, junto con fiscalizar el cumplimiento de las condiciones de los PAS, ha detectado incumplimientos en ellos, ejerciendo el mandato legal de levantar actas de infracción por sus fiscalizadores y denunciar estos incumplimientos ante el Juez de Policía Local competente. Lo anterior, ha generado críticas y solicitudes expresas formales de explicación por parte del Servicio de Evaluación Ambiental en la época ${ }^{4}$, al establecer que, por la creación de la nueva institucionalidad ambiental,

3 En efecto, a través de diversos oficios intercambiados entre la Dirección Regional de Coquimbo de CONAF y la Dirección Regional del Servicio de Evaluación Ambiental, se manifestó una disparidad de criterios evidente en torno a la solicitud de abstención a CONAF de levantar actas de fiscalización y denunciar a los Tribunales de Justicia las infracciones a la normativa forestal ocurridas con ocasión de proyectos sometidos al Sistema de Evaluación de Impacto Ambiental, con o sin Resolución de Calificación Ambiental dictada.

4 Servicio de Evaluación Ambiental Región de Coquimbo (2011), ORD. № CE/536, de 26 de Abril de 2011. 
el único con facultades de fiscalizar y sancionar sería el SEA5 , debiendo abstenerse CONAF de iniciar gestiones paralelas ante los Tribunales de Justicia, aludiendo, entre otros principios, al debido proceso y al non bis in idem, en razón de no castigar en forma simultánea, por la vía administrativa y judicial, un mismo hecho que, de subsistir ambos procedimientos, estaría siendo castigado dos veces ${ }^{6}$.

Por su parte, CONAF ha señalado, por vía formal, que no se abstendrá de ejercer y, en consecuencia, no dejará de cumplir el mandato que las leyes que regulan la actividad forestal le han conferido en forma imperativa; debido a que con ello se estaría incurriendo en falta de servicio por la institución, máxime cuando por la misma ley se configuran diversas infracciones y delitos que por su naturaleza deben ser de conocimiento de los Tribunales de Justicia. En este contexto, agrega que pesa sobre sus fiscalizadores y sus Directores Regionales la obligación legal de dar cuenta de estas infracciones, y denunciarlas ante dichos Tribunales, respectivamente ${ }^{7}$.

En cuanto a la normativa jurídica aplicable, en términos generales, este estudio buscará resolver la controversia, basándose para ello en las normas establecidas primeramente en los artículos 19 a 24 del Código Civil, y en la doctrina existente en torno a los principios de interpretación jurídica y el rol organizador de nuestro Ordenamiento Jurídico Ambiental; para arribar a una conclusión que resuelva el aparente conflicto de leyes que existe entre aquellas que regulan la institucionalidad ambiental y las que regulan la protección y conservación del patrimonio forestal del país, y que puede apreciarse entre las normas del D.L. 701 y sus modificaciones, además de la ley $\mathrm{N}^{\circ}$ 20.283 y sus reglamentos; y las leyes $\mathrm{N}^{\circ} 19.300$, sobre Bases Generales del Medio Ambiente, $\mathrm{N}^{\circ} 20.417$ sobre Nueva Institucionalidad Ambiental y $\mathrm{N}^{\circ} 20.600$, que crea los Tribunales Ambientales.

\section{Normas en aparente conflicto}

Desde la perspectiva de la normativa forestal, el D.L. 701, en su artículo 24 bis señala que con el mérito del acta que un fiscalizador haya levantado al constatar una infracción a la normativa forestal, “... el respectivo Director Regional de la Corporación deberá efectuar la correspondiente denuncia ante el tribunal competente, acompañando copia de dicha acta."

Por otro lado, el artículo 46 de la Ley de Bosque Nativo, № 20.283, repite exactamente la misma disposición, agregando que dicha denuncia, según sea el caso, deberá ser efectuada ante el Tribunal competente o el Ministerio Público.

Nos referimos a la época anterior al 28 de Diciembre de 2012, fecha en que la Superintendencia del Medio Ambiente comienza a ejercer sus facultades fiscalizadoras.

Servicio de Evaluación Ambiental Región de Coquimbo (2011), ORD. N ${ }^{\circ}$ CE/615, de 20 de Mayo de 2011.

Corporación NaCional Forestal Región de Coquimbo (2011), ORD No 49/2011, de 12 de Mayo de 2011. 
Por otro lado, nos encontramos con la normativa que acompańa la nueva institucionalidad ambiental en la materia. A fin de exponer el contrapunto, es necesario apreciar el texto del artículo 64 de la ley $\mathrm{N}^{\circ} 19.300$, el cual entrega a la Superintendencia del Medio Ambiente amplias facultades en materia de fiscalización ambiental.

En la misma línea, la Ley Orgánica de la Superintendencia del Medio Ambiente ${ }^{8}$, en su artículo $2^{\circ}$, señala que los organismos sectoriales conservan “...sus competencias y potestades de fiscalización, en todas aquellas materias e instrumentos que no sean de competencia de la Superintendencia..."

De lo señalado, se advierte la existencia de normas imperativas que obligan a CONAF a cumplir con sus funciones fiscalizadoras, denunciando a los infractores ante los Tribunales de Justicia en caso de así constatarlo, para que el Juez competente aplique la sanción que en Derecho corresponde. Estas normas, luego, estarían en contradicción con aquellas que rigen el actuar de la Superintendencia del Medio Ambiente, cuando se trata de fiscalizar proyectos sometidos al SEIA en los que se haya intervenido bosques, de manera que incluso las competencias específicas de ambos organismos pueden entrar en conflicto pese al inciso $2^{\circ}$ del artículo antes citado, si eso lo analizamos a la luz del artículo $3^{\circ}$ de la misma norma.

En tal sentido, se hace necesario solucionar esta aparente colisión de facultades por la vía de la interpretación.

\section{Resolución de la problemática jurídica}

En cuanto a controversia planteada, podemos señalar que la entrada en vigor de la Superintendencia de Medio Ambiente (SMA), no afectó el régimen de denuncia a los Juzgados de Policía Local de las infracciones a la legislación forestal por parte de terceros, manteniéndose vigente entonces la obligación legal que pesa sobre los Directores Regionales de CONAF en el país, obligación esta última que no puede soslayarse por la entrada en vigencia de la nueva institucionalidad ambiental. Lo anterior, se desprende de diversos argumentos de texto legal e interpretación armónica de las normativas, que son los que a continuación se pasan a desarrollar.

2. El artículo 59 de la LOSMA no es aplicable, por un criterio de generalidad.

Habiéndose planteado ya la problemática, vale la pena preguntarse: La entrada en vigor de la Superintendencia del Medio Ambiente, ¿Deroga la obligación de CONAF de denunciar las infracciones forestales en proyectos sometidos a una Resolución de Calificación Ambiental?

8 En adelante "LOSMA" (Nota del autor). 
Nos encontramos en condiciones de señalar que la respuesta a la interrogante es negativa. En los términos en que se expresa nuestro ordenamiento jurídico, CONAF permanece obligada a denunciar dichos incumplimientos a los Tribunales de Justicia, sin perjuicio de lo que expresamente señala el artículo 59 de la LOSMA. En otras palabras, dicho artículo, que establece una preferencia en favor de la SMA, respecto del conocimiento de hechos que sean causales de investigación administrativa por la vía de procedimientos sancionatorios, no es aplicable a la obligación legal expresa que existe en los artículos 24 bis del Decreto Ley $\mathrm{N}^{\circ} 701$ y 46 de la ley $\mathrm{N}^{\circ} 20.283$.

Ello, debido a que una interpretación armónica de la normativa nos dice que no se aplican las reglas de la derogación tácita u orgánica en este caso.

En efecto, frente a la interrogante de si una ley especial anterior es derogada por una ley general posterior, las dos principales tendencias de interpretación permiten llegar a la misma conclusión. Es decir, si hablamos de especialidad, la legislación forestal es especial frente a la legislación ambiental procedimental y orgánica, primando entonces el aforismo "lex posterior generalis non derogat priori speciali". Por otro lado, si nos acogemos al criterio que postula remitirse a la voluntad del legislador, o voluntas legis, es posible demostrar que el legislador no quiso intervenir en el actuar de los Tribunales de Justicia, respetando siempre su campo de acción; ya que el principal eje inspirador fue organizar y aglutinar las facultades fiscalizadoras de los organismos sectoriales, no así las de los Tribunales mencionados, que quedaron a salvo de ello. En tales términos -y como una excepción a la normativa- el artículo 59 referido no es aplicable en este caso, al existir texto expreso de ley especial en sentido contrario.

Las razones que fundan esta respuesta, se basan en las reglas de interpretación legal contenidas en los artículos 19 al 24 del Código Civil. Junto con ello, la doctrina extranjera ha establecido diversos criterios para resolver un conflicto de leyes, que ha denominado Antinomia".

Por Antinomia, se conoce a una "situación en que dos normas pertenecientes a un mismo sistema jurídico, que concurren en el ámbito temporal, espacial, personal y material de validez, atribuyen consecuencias juridicas incompatibles entre si a cierto supuesto fáctico, y esto impide su aplicación simultánea." ${ }^{10}$ Norberto BOBBIO, por su parte, la define como "... la situación en que dos normas incompatibles entre sí, pertenecen a un mismo ordenamiento, tienen un mismo ámbito de validez"II.

\footnotetext{
Castillo GonZález (2010).

Ibid.

Bоввіо (1999), p. 189.
} 
En este contexto, las diversas teorías que la doctrina ha vislumbrado para dilucidar conflictos de esta naturaleza, son las que se indican a continuación:

\subsection{Teorías de interpretación aplicables. Criterio de competencia de las normas}

En el caso de análisis, nos encontramos con un cuerpo legal reciente, cuyas disposiciones pugnan directamente con dos leyes anteriores a él que, como ya se ha señalado, regulan la obligación de CONAF de denunciar ante los Tribunales de Justicia los incumplimientos a los planes de manejo, y en general las infracciones a la legislación forestal. Mientras un grupo de normas, específicamente los artículos 24 bis del Decreto Ley $\mathrm{N}^{\circ} 701^{12}$, de 1979 , y 46 de la ley $20.283^{13}$, obligan a CONAF, específicamente a sus Directores Regionales, a denunciar a los Tribunales de Justicia las infracciones a las leyes referidas; el artículo 59, de la Ley Orgánica de la Superintendencia de Medio Ambiente ${ }^{14}$, señala que habiéndose iniciado un procedimiento administrativo sancionador por parte de la Superintendencia, no podrá ningún organismo sectorial con competencia ambiental, por los mismos hechos, iniciar un procedimiento administrativo sancionatorio de competencias propias, o denunciarlos a la justicia civil (el destacado es nuestro), a menos que la Superintendencia se declare incompetente ${ }^{15}$. Es

12 En su texto sustituido por el D.L. 2565 de 1979, y modificado por la ley $\mathrm{N}^{\circ} 19.561$, de 1998, señala: "Artículo 24 bis.- Detectada una infracción de las disposiciones de esta ley o de su reglamento, los funcionarios de la Corporación deberán levantar un acta en que se consignarán los hechos constitutivos de la infracción, indicando el día, lugar, fecha y hora de la diligencia inspectiva, la circunstancia de encontrarse o no presente el supuesto infractor o su representante legal, así como la individualización de éste, su domicilio, si ello fuere posible, y las normas legales contravenidas.

Con el mérito del acta referida en el inciso primero, el respectivo Director Regional de la Corporación deberá efectuar la correspondiente denuncia ante el tribunal competente, acompañando copia de dicha acta".

13 "Artículo 46.- Detectada una infracción a las disposiciones de esta ley o de su reglamento, los funcionarios de la Corporación deberán levantar un acta en que se consignarán los hechos constitutivos de la infracción, indicando el día, lugar, fecha y hora de la diligencia inspectiva, la circunstancia de encontrarse o no presente el supuesto infractor o su representante legal, así como la individualización de éste, su domicilio, si ello fuera posible, y las normas legales contravenidas.

Con el mérito del acta referida en el inciso primero, el respectivo Director Regional de la Corporación deberá efectuar la correspondiente denuncia ante el tribunal competente o al Ministerio Público, según sea el caso, acompañando copia de dicha acta..."

14 "Artículo 59.- Iniciado un procedimiento administrativo sancionador por parte de la Superintendencia no podrá ningún organismo sectorial con competencia ambiental, por los mismos hechos, iniciar un procedimiento administrativo sancionatorio de competencias propias o denunciarlos a la justicia civil, a menos que la Superintendencia se declare incompetente.

Los organismos sectoriales con competencia ambiental que, en el ejercicio de sus funciones, tomen conocimiento de estas infracciones estarán obligados a denunciarlos a la Superintendencia. En caso de que alguno de estos organismos iniciare un procedimiento respecto de materias que son competencia de la Superintendencia, ésta, de oficio o a petición de interesado, podrá solicitarle que se declare incompetente y le remita todos los antecedentes para iniciar el procedimiento respectivo".

15 Artículo 59, Ley Orgánica de la Superintendencia de Medio Ambiente., contenida en la Ley N 20.417 , artículo segundo. 
decir, si el analista se conformara con la simple primera lectura, podría llegar a concluir que ambas leyes no podrían aplicarse en forma simultánea.

La doctrina ha señalado que, en casos como éste, para lograr determinar el real sentido en que estas normas deben interpretarse armónicamente, la aparente dicotomía debe ser apreciada, primero, desde el punto de vista de la competencia sobre las áreas del Derecho que regulan y, segundo, desde el punto de vista de los servicios públicos que son objeto de ellas.

De los criterios de interpretación que la doctrina ha delineado ${ }^{16}$, a nuestro parecer, el aparente dilema es solucionable por la vía de la determinación de las competencias que a ambos grupos de cuerpos normativos se ha confiado por el legislador. Lo anterior, se explica porque el caso en análisis cumple con los requisitos para la aplicación de los presupuestos necesarios para una solución interpretativa de esta naturaleza, que son los siguientes:

\subsubsection{Que se produzca un conflicto entre normas provenientes de fuentes de tipo diverso}

En el caso que nos ocupa, el determinar el origen diverso de las fuentes se complica aparentemente, puesto que formalmente las obligaciones y restricciones que se analizan provienen de un mismo tipo de fuente formal, ya que ambas provienen de una ley. No obstante ello, sus fuentes materiales son diversas en una y otra, lo que hace que el origen en definitiva sea a su vez diverso, cumpliendo así con este presupuesto.

En efecto, estos mismos cuerpos normativos nacen de fuentes materiales distintas, toda vez que su motivación es variada. Mientras las obligaciones de CONAF están inspiradas en la regulación y fomento de la explotación forestal, y en la explotación razonable y sustentable de la vegetación nativa de nuestro país; la acción fiscalizadora de la Superintendencia del Medio Ambiente ${ }^{17}$ fue inspirada en el reordenamiento del sector ambiental en general, con una visión orgánica que, para el caso que nos ocupa, se orientaría no exclusivamente al campo forestal, sino que a todos los elementos que componen el ecosistema; buscando siempre tener presente criterios de sustentabilidad en el aprovechamiento de los recursos sin vulnerar lo dispuesto en el artículo 19, número 8, de nuestra Constitución Política.

\footnotetext{
Castillo González (2010).

En adelante SMA (Nota del autor).
} 


\subsubsection{Que entre las dos fuentes en cuestión no exista una relación} jerárquica (por estar dispuestas sobre el mismo plano en la jerarquía de las fuentes)

Al analizar la historia fidedigna del establecimiento de la Ley $\mathrm{N}^{\circ} 20.417$, es posible concluir que las normas en conflicto son del mismo rango, es decir, leyes simples, sin que ninguno de los artículos en conflicto tenga el rango de ley orgánica constitucional. Lo anterior fue ratificado en el fallo del Tribunal Constitucional, quien se pronunció en ese tenor al momento de hacer el control de constitucionalidad ${ }^{18}$, y que no se pronunció sobre los artículos 59 y 60 de la ley referida para indicar que alguna de ellas tuviera dicho rango.

Adicionalmente, y a mayor abundamiento, al momento de ser propuesto el proyecto de ley en sala en la Cámara de Diputados, durante el primer trámite legislativo, al inicio de la discusión ${ }^{19}$, se determinó que los artículos 59 y 60 no son normas orgánicas constitucionales.

\subsubsection{Que las relaciones entre las dos fuentes estén reguladas por} otras normas jerárquicamente superiores, atribuyendo -y de esa forma, reservando- a cada una de ellas una diversa esfera material de competencia, de modo que cada una de las dos fuentes tenga la competencia exclusiva para regular una cierta materia.

Ambas normas reconocen su normativa superior en la Constitución Política, regulando cada una de ellas, como ya se indicara, planos diversos de la actividad del país, en planos diversos que se entrecruzan armónicamente, sin contraponerse.

\subsection{Criterio de especialidad}

Se hace necesario dilucidar cuál de las normas en conflicto es general y cuál es especial. Para ello, hay que partir de la base que la generalidad o especialidad de las normas dependerá del contexto en que esta distinción sea propuesta. Así, la normativa ambiental relativa a la nueva institucionalidad ambiental será especial frente al resto del ordenamiento jurídico, si el contexto en que se plantea esta relación es el ordenamiento jurídico en su totalidad.

18 Sentencia de 6 de enero de 2010, recaída en los autos Rol No 1.554-09-CPR del Tribunal Constitucional.

19 Congreso Nacional de la República de Chile (2010), pp. 23 - 29, p. 474. 
En ese mismo predicamento, si la discusión entre especialidad y generalidad se da en el contexto exclusivo de la legislación ambiental, el panorama es distinto. Por Derecho Ambiental, en una de sus más recientes definiciones, podemos entender al "Conjunto de disposiciones que pretenden regular la subsistencia del ser humano en el planeta"20 o el "Conjunto de principios, leyes, normas y jurisprudencia que regulan la conducta humana dentro del campo ambiental’"1 como lo define el profesor FERNÁNDEZ. Así, esta rama del Derecho pasa a ser la norma general, ya que en sus disposiciones buscará ordenar el comportamiento humano en los diversos sectores que regula; ya sea minería, urbanismo y construcciones, pueblos originarios, normas de calidad ambiental o aprovechamiento sustentable de los recursos naturales, entre los que consideramos naturalmente sectores como la industria siderúrgica, pesquera o forestal, cada una de ellas con su propia regulación.

Cada uno de los proyectos que se someten al SEIA, tiene su propio grupo de normas especiales a que debe sujetarse, y que son recogidos por el reglamento del referido sistema, de manera que cada sector emite los actos administrativos que corresponda, que no son otros que los permisos ambientales sectoriales, (PAS) Estos actos administrativos ${ }^{22}$ hacen referencia en sus disposiciones a diversos aspectos establecidos en leyes y reglamentos del sector de que se trate, y dentro de estos sectores naturalmente en el sector forestal, también los PAS respectivos harán referencia a la legislación del sector. De tal manera que, ante un incumplimiento de una recomendación y exigencia contenida en una Resolución de Calificación Ambiental (en adelante, también "RCA") basada en un PAS emitido por CONAF, se generará un doble proceso, pero en lo que nos ocupa en este punto, dará cuenta de la existencia de una infracción que es propia de este sector, con un objeto propio de Derecho, y que frente a la legislación ambiental evidentemente será una rama con leyes especiales, como es la normativa forestal.

Resuelta esta disyuntiva, siguiendo con el desarrollo de esta hipótesis, nos encontramos ante un camino más llano que refuerza la no derogación de la normativa, que no es otra que la respuesta a la amplia discusión acerca de si una ley general posterior deroga una ley especial anterior. En este caso vale la pena preguntarnos, una vez más y desde este nuevo punto de vista, si la ley 20.417 deroga las disposiciones especiales contenidas en el Decreto Ley $N^{\circ} 701$ y la ley 20.283, ambas normas materia de este estudio.

Recordando lo ya tratado en párrafos anteriores, haremos el análisis desde los dos puntos de vista, según los cuales se ha buscado solucionar una controversia de esta naturaleza. Es decir, la controversia puede resolverse tanto desde el punto de vista del

22 En el entendido que son actos jurídicos emitidos por órganos de la Administración del Estado, se encuentran dotados de tal calidad. En el mismo sentido, Juan Francisco BASCUÑáN, en un trabajo editado por el Centro de Derecho Ambiental de la Universidad de Chile, en conjunto con la ex CONAMA, define a los Permisos Ambientales Sectoriales (en adelante "PAS") como "el conjunto de autorizaciones que el ordenamiento jurídico contempla, desde antes de la entrada en vigencia de la referida ley y que poseen un contenido ambiental”. En: Bascuñan (2001), p. 71. 
aforismo lex posterior generalis non derogat priori speciali, como desde el punto de vista de la voluntas legis.

\subsubsection{Análisis desde el punto de vista del aforismo lex posterior generalis non derogat priori speciali}

Sabido es que un sector de la doctrina ${ }^{23}$ se apoyaba en este aforismo, que plantea que una ley posterior que es general no deroga una ley especial, aunque esta última sea anterior. Siguiendo el mismo criterio, la tarea a resolver es determinar cuál ley de las que han sido materia del presente estudio debe ser catalogada como general y cuál como especial. La dificultad se torna mayor cuando se trata de leyes que rigen una rama del Derecho que se considera como especial dentro del resto del ordenamiento jurídico. No obstante, intentaremos resolver esta encrucijada de la manera que indicaremos a continuación.

Tal como se dijera párrafos más arriba, el concepto de generalidad y especialidad es relativo, según el contexto en el que se trate. En el caso del Derecho Ambiental, si bien es una rama especial del Derecho frente al resto del ordenamiento jurídico, en el contexto mismo del Derecho Ambiental podemos distinguir diversas sub-ramas, compatibles con los diversos sectores y actividades económicas que regula. Estas subramas tienen su propia normativa que se ajusta en su actuar a esta rama del Derecho.

En este contexto entonces, el Derecho Ambiental, en cuanto a sus normas de Derecho Adjetivo, tales como las que regulan la institucionalidad sobre la cual va a regir, pasa a ser la normativa general de esta rama del Derecho, ya que regulará la forma en que los proyectos del sector de que se trate deban obtener una calificación favorable por medio del acto administrativo correspondiente. A su vez, cada sector de la economía tendrá su propia normativa particular que ya existe, y entre ellas nos encontraremos con las normas del Derecho Forestal, que en este caso pasarán a tener la calidad de especiales o sustantivas frente a la norma general antes descrita.

Dentro del Derecho Forestal, que se topa en una relación de especialidad con el Derecho Ambiental, existen las normas que obligan a CONAF a denunciar los incumplimientos forestales al Juez de Policía Local competente, que pasan a ser especiales y regulan aspectos claramente específicos que en muchas ocasiones pasarán a ser independientes de la existencia o no de una RCA. En este contexto, la que llamaremos "ley general" es aquella que establece en su artículo 59 del artículo segundo de la ley 20.417 la prohibición de denunciar a la justicia civil por los mismos hechos por los que se haya iniciado un procedimiento sancionador por la SMA, mientras ésta no se declare incompetente.

Sin perjuicio de explayarnos más adelante acerca de la voluntad del legislador, podemos decir que, en una interpretación armónica de estas normas, el Decreto Ley 701 y la 
ley 20.283 son especiales en relación al artículo 59 de la LOSMA antes referido, de manera que aquellas perviven frente esta última que, en el contexto de esta premisa, es una norma de carácter general.

De esta manera, la antinomia se resuelve en favor de la especialidad de la normativa Forestal, que pasa a ser sustantiva frente al Derecho Ambiental adjetivo u organizador; de manera que la prohibición de denunciar rige para la generalidad de los casos de otros sectores de la economía que se encuentren regulados, salvo para los casos puntuales del D.L. 701 y la ley 20.283, los cuales se encuentran regidos por su legislación especial. En otras palabras, para el caso de estudio, las obligaciones de denunciar contenidas en las normas forestales no deben entenderse derogadas por la normativa que empezó a regir al momento del inicio del funcionamiento de las instituciones referidas en la ley $\mathrm{N}^{\circ} 20.417$.

De esta manera, en cuanto a las infracciones a la legislación forestal, los Directores Regionales deberán seguir cumpliendo con su obligación legal de denunciar ante los Tribunales de Justicia, apenas tengan conocimiento de las actas levantadas por los fiscalizadores autorizados por ley. Para el caso que dicho incumplimiento además vulnere obligaciones contenidas en una RCA, sujeta en consecuencia al ámbito de competencia de la SMA, la denuncia a los Tribunales de Justicia antes seńalada se hará con absoluta independencia del inicio o no de procedimientos sancionatorios por parte de aquel ente rector.

En un caso real, con motivo del expreso cuestionamiento del SEA a las facultades de CONAF sobre la materia, por incumplimientos a la ley forestal ocurridos en la Región de Coquimbo, la Dirección Regional de este último organismo entregó, en su respuesta, las razones por las cuales estima que dichas facultades se mantienen vigentes, precisamente por mandato legal. Así, en su oficio ORD. 49/2011, de 12 de Mayo de 2011, de la Dirección Regional de CONAF a la Dirección Regional del SEA, ambos de la región ya mencionada, el organismo señala:

“...el Decreto Ley N 701 y la Ley N²0.283, sobre recuperación del Bosque Nativo y Fomento Forestal, entregan a CONAF, como organismo del Estado, una activa participación y atribuciones de carácter público, en todo lo relativo al control de la corta o explotación de bosques, al fomento de la forestación y en especial a la fiscalización de la actividad forestal en Chile." ${ }^{24}$

"De lo expuesto, se desprende que la Corporación Nacional Forestal, es la institución del Estado a cargo del tema forestal, encargándose por mandato legal, de elaborar y proponer normativa para el sector forestal, administrar los principales instrumentos de intervención del Estado en el ámbito forestal, a saber, el sistema de bonificación a la actividad forestal, y la Fiscalización del cumplimiento de la normativa existente."25 
"Es así como los artículos 24 del Decreto Ley Nº 701 y 46 de La Ley de Bosque Nativo, disponen que, detectada una infracción, los funcionarios de la Corporación deberán levantar un acta que consignen los hechos constitutivos de la infracción, indicando el día, lugar, fecha y hora de la diligencia e individualizando al posible infractor y las normas legales contravenidas. Con dichos antecedentes el Director Regional de la Corporación deberá efectuar la correspondiente denuncia los tribunales competentes." ${ }^{26}$

Precisamente es esta postura la que suscribimos en este artículo, y que se desarrollará en las conclusiones. Como se verá más adelante, el daño que se produce es al ordenamiento jurídico, y que va más allá de lo que se puede entender como el fenómeno de "Propietarización de Facultades Públicas" los artículos 59 y 60 de la Ley Orgánica de la SMA puede minar la efectividad de disposiciones concebidas para fines específicos que son distintos de los perseguidos por la SMA en su ley orgánica.

Junto con ello, el impedir deliberadamente la aplicación de una normativa expresa, -como son la ley de bosque nativo y la ley de fomento forestal en lo que a nosotros concierne-, eventualmente provocará el efecto de que los órganos obligados a cumplirla incurrirán en sanciones por falta de servicio, en las formas ya explicadas en párrafos anteriores. Si lo que se busca es eliminar esta obligación cuando se trate de condiciones o medidas impuestas a un titular en una RCA, la vía correcta es derogarlas por texto expreso para tales circunstancias, como se explicará más adelante, y no continuar con lo que -a nuestro entender- es una antinomia sin aparente solución.

\subsubsection{Análisis desde el punto de vista voluntas legis}

Si se descartara la argumentación anterior, la historia fidedigna del establecimiento de la ley nos lleva a igual conclusión que la propuesta en este trabajo. Es decir, la voluntad del legislador, en orden a acumular las competencias normativas y fiscalizadoras en un solo organismo, se refirió siempre al campo de la Administración del Estado y no incluyó a los Tribunales de Justicia en su tarea sancionadora. En esos términos, el reordenamiento se propuso en el contexto de que la Administración del Estado, en cuanto a materias de medio ambiente, y siempre a un nivel superior de organización, ordenara el funcionamiento de los servicios sectoriales, de manera que éstos se acoplaran en general

\footnotetext{
Corporación Nacional Forestal, Región de Coquimbo, (2011): ORD Nº 49/2011.

Definida por la entonces CONAMA, en un documento de trabajo de dicha institución, como la “...reticencia de los funcionarios de los ministerios a asumir la política ambiental general porque ellos responden a sus políticas sectoriales". En: Comisión Nacional del Medio Ambiente, Región de Atacama (2007). [en línea]: Documento de Discusión. Proceso de Participación Ciudadana en la Generación de una nueva institucionalidad ambiental Para Chile. [Fecha de consulta: 10 de julio de 2013]. Disponible en: <http://www.sinia.cl/1292/articles-40545_recurso_1.pdf>
} 
a las disposiciones e instructivos de la Superintendencia y colaboraran a la actuación de este último ente rector ${ }^{28}$.

Así, este ideal de organización administrativa siempre dejó a salvo las potestades de los Tribunales de Justicia, ya que se entendió que no era posible intervenir en sus facultades de conocer las causas civiles y criminales, juzgarlas y hacer ejecutar lo juzgado. Sin ir más lejos, los informes de la Corte Suprema, opinando sobre el proyecto, fueron desfavorables (el segundo y tercer informe), toda vez que observaron que el conocimiento del procedimiento contencioso administrativo debía mantenerse en un Juez de Letras en lo Civil. ${ }^{29}$ El mismo predicamento puede entenderse aplicable en cuanto a la intervención del conocimiento de las infracciones forestales por los Jueces de Policía Local y, en consecuencia, puede estimarse también improcedente la aplicación "a tabla rasa" de lo dispuesto en el artículo 59 ya mencionado. Si bien tal observación no la encontramos expresamente en la historia fidedigna, es posible inferir que hubiésemos tenido la misma respuesta del máximo Tribunal de la República, en caso de haberse consultado aquello.

En este orden de cosas, es pertinente rescatar la intervención del Honorable Diputado Alberto ROBLES en sala, al momento de discutir acerca de la idea de legislar -cuando se refería a la necesidad de crear tribunales ambientales que compensaran las facultades de la Superintendencia- y lo planteado por las comisiones legislativas. A decir de la propia comisión, el tema del ordenamiento de facultades y unificación de procedimientos de fiscalización es un cuestionamiento solamente administrativo, porque no apunta a la contienda legal propiamente tal, debido a que esta última es algo que corresponde a los tribunales ${ }^{30}$.

Es decir, la voluntad del legislador siempre ha sido no intervenir en las facultades de los Tribunales de Justicia, ni menos restringirlas en forma absoluta. De la misma forma en

28 Se planteó en el trabajo de comisiones que la perpetuación de las facultades fiscalizadoras de los organismos sectoriales continuaría produciendo un problema de múltiple fiscalización y dispersión de facultades, causando perjuicio a las actividades productivas y redundando en aumento de costos e ineficiencia de los procedimientos empresariales. El proyecto de ley no contemplaba claramente la superioridad de la superintendencia sobre los organismos sectoriales, proponiendo como solución para ello la mantención de las competencias fiscalizadoras de los organismos sectoriales, pero suspendiendo indefinidamente su ejercicio, condicionándolo a una instrucción expresa de la Superintendencia. Congreso Nacional de la República de Chile, p. 161. Congreso Nacional de la República de Chile, op. cit. p. 671

30 El Hon. Diputado Alberto ROBLES, en la discusión en sala, expresó lo siguiente, según figura en actas: “... Entiendo que se pretende apuntar a un aspecto más técnico; pero las iniciativas ambientales tienen también mucho sentido político. Por eso, aquí hay un punto que debiéramos mejorar y buscarfórmulas para solucionar un aspecto dejado de lado. En efecto, lo local se deja de lado por esta técnica puesta en escena que, aunque comparto en gran medida, al no considerar otro aspecto implica una falencia seria.

El otro tema que quiero plantear, que también se relaciona con una mirada de Estado, que involucra a todos, no sólo al Gobierno, es la capacidad que tendrá la Superintendencia no sólo de fiscalizar, sino, además, de sancionar. Es decir, será juez y parte de sus propias decisiones.

Me parece que en el último tiempo el Estado de Chile ha cambiado esa mirada medio arcaica de superintendencias del siglo pasado y, por lo tanto, debiera avanzar hacia superintendencias nuevas. Se me explicó en la Comisión que las

superintendencias actuales tienen el rol de fiscalizar y sancionar; pero, si estamos avanzando en el siglo XXI con un sistema de justicia distinto, donde hay un fiscal económico que revisa, controla y fiscaliza lo concerniente a la parte económica del país, y un tribunal distinto que sanciona ipor qué no podemos crear un tribunal medioambiental con personas competentes, capacitadas, de distintos sectores, de manera de contar con una 
que circunscribió el non bis in idem al campo de los procedimientos administrativos ${ }^{31}$, el legislador quiso conservar las facultades de los Tribunales de Justicia; con la salvedad de que conocieran de las infracciones civiles una vez que se hubieran resuelto los procedimientos administrativos, salvo aquellas ocasiones en que, por norma expresa, los Tribunales no deban esperar su resolución para conocer de ellas, como el caso en estudio. Es decir, si atendemos a la voluntad del legislador, tampoco podemos concluir que la normativa en estudio haya sido derogada tácitamente. ${ }^{32}$

\subsection{Naturaleza jurídica de las sanciones y su origen diverso}

Desde el punto de vista de las sanciones con que puede culminar uno y otro procedimiento, no se ve tampoco obstáculo para que una interpretación armónica de las normas permita mantener vigentes las obligaciones de CONAF de denunciar las infracciones a la legislación forestal.

De hecho, si analizamos las sanciones que aplica la SMA, nos encontraremos que ellas son de carácter administrativo, y se encuentran contenidas en los artículos 38 y 39 de su ley orgánica33. Este proceso se inicia de oficio por la SMA luego de una

cierta sanidad en términos del control y la fiscalización fuerte que debe tener la Superintendencia, pero con un poder sancionatorio distinto que permita contar con un contrapeso desde el punto de vista administrativo? Se me dijo que esto es solamente administrativo porque no apunta a la contienda legal propiamente tal, que corresponde a los tribunales.

Pero si en lo administrativo, en todo el aparato público, hace mucho tiempo se creó, un sistema de sanción distinto al que ejecuta la administración propia de los servicios, cual es la Contraloría, que interpreta, revisa e incluso puede sancionar en forma distinta a un servicio, entonces ¿por qué no tener un tribunal ambiental, que pueda sancionar en forma distinta de cómo lo hará el fiscalizador?

Esos dos roles deben separarse. Se separaron en el área judicial; boy, el fiscal indaga; hay un juez de garantía, y otros jueces -no un juez único- constituyen la primera instancia y determinan en forma distinta. Separamos el rol de quien fiscaliza respecto de quien juzga. Entonces, ¿por qué no bacerlo también respecto del medio ambiente? ¿Es un paso muy osado? Creo que no". Historia de la Ley $N^{\circ} 20.417$, En: Congreso Nacional de la República de Chile, p. 505. (ver ibid, nota 59).

31 Tal y como lo señala el artículo 60 de la LOSMA (Nota del autor).

32 A la misma conclusión puede arribarse si se analiza el proyecto de ley que crea el Servicio de Biodiversidad y Areas Protegidas, contenido en el boletín 9404-12, del Congreso Nacional. Luego de examinar su articulado, podemos concluir que la creación de este servicio, en los términos que establece el proyecto de ley, y sin perjuicio de las indicaciones que se le hagan durante su tramitación, no modifica sustancialmente el escenario planteado en el presente trabajo, en lo relativo a las competencias de este nuevo servicio, la Superintendencia de Medio Ambiente y la Corporación Nacional Forestal. El proyecto, sólo incorpora a los administradores de las áreas que estarán a cargo de nuevo servicio dentro de aquellos que pueden denunciar las infracciones a las leyes que ocurran dentro de las áreas bajo su administración, entre ellas las leyes forestales como las que han sido analizadas dentro de este trabajo, y que también, en lo pertinente, pasan a ser modificadas por este nuevo proyecto de ley. De esta manera, la obligación de los Directores Regionales de CONAF permanece vigente, sumando en el proyecto de ley a los administradores de áreas protegidas dentro de los funcionarios obligados a denunciar a la autoridad correspondiente dichas infracciones. Por otro lado, al modificarse sólo parcialmente el artículo 46 de la ley de bosque nativo, los directores regionales de CONAF conservarían intacta su obligación de denunciar a los Juzgados de Policía Local las infracciones que a dichos directivos le informen los fiscalizadores de su institución, respecto de la normativa contenida en la ley $\mathrm{N}^{\circ} 20.283$.

33 “...Artículo 38.- Las infracciones cuyo conocimiento compete a la Superintendencia, podrán ser objeto de las siguientes sanciones:

a) Amonestación por escrito.

b) Multa de una a diez mil unidades tributarias anuales. 
fiscalización o por denuncia de terceros, dando lugar a la formación de un expediente administrativo, que puede terminar con la aplicación de sanciones por parte de un órgano administrativo -como lo es el Superintendente-, respecto de las cuales puede reclamarse ante el Tribunal Ambiental, tercero imparcial, iniciándose con ello el proceso jurisdiccional, luego de haber culminado el procedimiento sancionatorio dentro de la esfera de la Administración.

Frente a ello, nos encontramos con un procedimiento distinto, en que los actores también son diferentes. De hecho, el proceso ante los Tribunales de Justicia por incumplimientos a la normativa forestal, en la mayoría de los casos por corta ilegal, se inicia por la denuncia que hace el Director Regional de CONAF competente, luego de haberse levantado las actas de infracción a la normativa forestal, donde esta institución actúa como parte denunciante durante todo el proceso, que se sustancia ante un tercero imparcial -un Juez letrado- que aplica una sanción establecida en la ley, por medio de una sentencia judicial, que condenará al infractor en definitiva a pagar las multas que indique y eventualmente a reforestar lo dańado.

Es necesario señalar que, si bien en el caso de estudio la dicotomía aparente se manifiesta en el contexto de la fiscalización de un proyecto calificado por una RCA, ambas sanciones son de naturaleza jurídica distinta (administrativa una y judicial la otra), por lo que no se contraponen ni se anulan, ya que, como se verá, están enfocadas a lograr objetivos distintos establecidos por el legislador, en planos diversos como lo son el cumplimiento de las condiciones establecidas en una RCA -por un lado-, y el cumplimiento de la normativa forestal, -por otro-.

\section{No es aplicable el artículo 60 de la LOSMA, por ausencia del non bis in idem}

De la misma forma, es posible concluir que el artículo 60, en cuanto a la aplicación del principio del non bis in idem, no corre el riesgo de ser vulnerado. La normativa ambiental y la normativa forestal persiguen la protección de bienes jurídicos diversos, y los castigos que se aplican nacen de procedimientos de naturaleza y sustanciación diversa, son aplicados por autoridades que derivan de poderes del Estado que son distintos entre sí y la entidad de las sanciones igualmente difiere en cuanto a su naturaleza

c) Clausura temporal o definitiva.

d) Revocación de la Resolución de Calificación Ambiental.

Artículo 39.- La sanción que corresponda aplicar a cada infracción se determinará, según su gravedad, dentro de los siguientes rangos:

a) Las infracciones gravísimas podrán ser objeto de revocación de la resolución de calificación ambiental, clausura, o multa de hasta diez mil unidades tributarias anuales.

b) Las infracciones graves podrán ser objeto de revocación de la resolución de calificación ambiental, clausura, o multa de hasta cinco mil unidades tributarias anuales.

c) Las infracciones leves podrán ser objeto de amonestación por escrito o multa de una hasta mil unidades tributarias anuales..." 
jurídica. Por lo demás, la voluntad del legislador, a juzgar por la historia fidedigna de su establecimiento ya analizada, se inclina por que esta prevención de non bis in idem es aplicable sólo para infracciones y sanciones de carácter administrativo, lo que se explica en atención a la aglutinación de facultades fiscalizadoras y sancionadoras en la Superintendencia de Medio Ambiente.

\subsection{Ausencia de non bis in idem, diversidad de bienes jurídicos protegidos en uno y otro caso}

El aforismo non bis in idem postula que una persona no puede ser juzgada dos veces por los mismos hechos que se consideran delictuosos, a fin de evitar que quede pendiente una amenaza permanente sobre el que ha sido sometido a un proceso penal anterior.

En otras palabras, es un impedimento procesal que niega la posibilidad de interponer una nueva acción, y la apertura de un segundo proceso con el mismo objeto. Es un impedimento, que niega la posibilidad de interponer una nueva acción, y la apertura de un segundo proceso con el mismo objeto, de tal modo que una misma acción no puede hacerse valer en dos ocasiones, cualquiera que fuese el resultado del primer procedimiento que le fuera iniciado al acusado.

Este principio, nacido en el Derecho Penal, con el tiempo ha extendido su aplicación a otras ramas del Derecho. No obstante lo anterior, es necesario distinguir los diversos planos por los que se puede sancionar un hecho, para recién determinar la vigencia o no de las facultades y obligaciones contenidas en la ley, y que nacen para las instituciones a que se refiere el presente estudio.

Contra lo que se pudiera concluir, luego de una primera lectura al artículo 59 del artículo segundo de la ley 20.417, nos encontramos en condiciones de señalar que, en la controversia sometida a análisis, no se dan los presupuestos del non bis in idem que impidan la denuncia a los Tribunales de Justicia, por parte de CONAF, de los incumplimientos a la legislación forestal que configuren infracciones a la normativa, en los términos que indica el artículo 60 del artículo segundo de la ley $\mathrm{N}^{\circ} 20.417$.

En efecto, el artículo indica en su inciso segundo que "...En ningún caso se podrá aplicar al infractor, por los mismos hechos y fundamentos jurídicos, dos o más sanciones administrativas". Es decir, la restricción se circunscribe sólo al plano de la Administración del Estado, lo que concuerda con el propósito del legislador, que buscaba regular la diseminación administrativa de procedimientos y sanciones que diversos órganos podían aplicar ante una infracción a un incumplimiento de la normativa ambiental, para reunirlos en un solo procedimiento regulado y sustanciado por una sola institución, 
como lo es la Superintendencia, sin intervenir en las actuaciones que por ley le competen al Poder Judicial. ${ }^{34}$

Lo anterior, porque la base de la problemática que buscamos resolver a través del presente informe radica en que las sanciones que presumiblemente entran en cuestión en virtud del principio de non bis in idem son de diversa naturaleza jurídica, de manera que, al no calificar dentro de la restricción señalada, ambos procesos -administrativo y judicial- pueden iniciarse incluso en forma simultánea, al ser factibles de sustanciarse por cuerda separada.

En efecto, nos encontramos, por una parte, con toda la batería de sanciones con que cuenta la Superintendencia del Medio Ambiente, aplicadas luego de la sustanciación del respectivo expediente administrativo, y que son sanciones administrativas aplicadas por el jefe del servicio por vía de resoluciones exentas reclamables ante el Tribunal Ambiental competente, y que han sido motivadas por un propósito, causa y alcance que se encuentran determinados por el ámbito de competencia de la Superintendencia, ámbito que se circunscribe principalmente a la fiscalización del correcto cumplimiento de las obligaciones contenidas en una RCA y del respeto a las normas ambientales.

Frente a ello, las sanciones que aplica un Tribunal de Justicia, en este caso los Juzgados de Policía Local, son aplicadas por un órgano que no pertenece a la administración del Estado, -un Juez de la República, facultado para impartir justicia y no solamente ejercer jurisdicción-, y que se materializan en la dictación de sentencias judiciales. Su motivación, su causa, radica en el correcto cumplimiento y respeto a las normas sobre fomento y protección forestal existentes en el D.L. 701 sobre Fomento Forestal, y la ley $\mathrm{N}^{\circ} 20.283$ sobre Bosque Nativo y el castigo a las infracciones que se cometan cuando se vulnere esta normativa.

Finalmente, ambos tipos de sanciones están concebidas para proteger bienes jurídicos diversos entendiendo, por "bien jurídico", a todo aquello que puede satisfacer una necesidad humana, que genera un interés que es reconocido como social o moralmente valioso por el legislador, quien le brinda en consecuencia su protección, prohibiendo las conductas que lo lesionen. ${ }^{35}$

En este caso, la normativa forestal está orientada a proteger el recurso bosque, formaciones xerofíticas, suelo y agua, entendido todo como una sola unidad, siendo este complejo

34 Durante la tramitación del proyecto de ley, se planteó la necesidad de contar con un sistema eficaz y eficiente, y que se hiciera cargo de los problemas que ocasionaba una fiscalización dispersa que hacían diversos organismos, que hacían más oneroso y deficiente esta tarea, al no contar con la información adecuada para realizar esta función. El espíritu general de la iniciativa, fue concentrar las potestades fiscalizadoras en un solo organismo especializado, a cargo de la dirección absoluta del sistema de fiscalización, al cual los demás organismos competentes deberían estar supeditados. A decir de la propia comisión, el tema es solamente administrativo, porque no apunta a la contienda legal propiamente tal, que corresponde a los tribunales. En Congreso Nacional de la República de Chile, op. Cit. pp. 101, 161 y 505.

35 Esto, en el entendido que un bien es todo aquello que puede satisfacer una necesidad humana, material o ideal (individual o social). Un interés es la posición de un sujeto frente a un bien. Así, el fin de la norma, y del ordenamiento jurídico, es la protección de los intereses, según Etcheverry (1997). 
su bien jurídico protegido; una dimensión necesaria para asegurar la producción sustentable de la industria forestal del país y para evitar consecuencialmente el deterioro de los suelos y la pérdida del recurso hídrico. ${ }^{36}$ En cambio, la Ley $N^{\circ} 20.417$, de nueva institucionalidad ambiental, fue concebida con objetivos distintos, buscando proteger bienes jurídicos en un plano distinto, como lo es la eficiente y eficaz conservación y preservación del medio ambiente en general, a través de la reorganización del aparato administrativo fiscalizador y creador de políticas ambientales. Bienes jurídicos diversos, que evidentemente motivan el inicio de procedimientos diversos, que culminan en la aplicación de sanciones de diversa naturaleza jurídica en ámbitos totalmente diversos; los cuales, lejos de cruzarse, contraponerse o entrar en conflicto, se complementan armónicamente, pudiendo coexistir sin restricciones o interferencia entre sí.

\section{Conocimiento preferente de las infracciones, previo a las denuncias ante la Justicia, y riesgo de incurrir en "falta de servicio" por parte de CONAF}

Nuestra Constitución señala claramente, en su artículo 76, que pertenece exclusivamente a los Tribunales de Justicia la facultad de conocer las causas civiles y criminales, resolverlas y hacer ejecutar lo juzgado, remarcando que ni el Presidente de la República ni el Congreso pueden en caso alguno ejercer funciones judiciales, entre otras restricciones 37 .

Nos inclinamos por pensar que este principio de independencia del Poder Judicial le da además primacía a los Tribunales de Justicia, ya que una interpretación literal del artículo 6038 genera un fenómeno que no es saludable en atención a la imparcialidad de los Tribunales. En efecto, en el supuesto anterior, la Magistratura conocería en forma posterior la sanción impuesta por la Superintendencia, pudiendo ello afectar la apreciación prístina de los hechos en las materias que sean de su competencia,

36 Así, el Decreto Ley 701 sobre Fomento Forestal, tiene por objeto regular la actividad forestal en suelos de aptitud preferentemente forestal y en suelos degradados, e incentivar la forestación, en especial, por parte de los pequeños propietarios forestales, y aquella necesaria para la prevención de la degradación, protección y recuperación de los suelos del territorio nacional. Por su parte, la ley $\mathrm{N}^{\circ} 20.283$ recuperación del Bosque Nativo y Fomento Forestal, tiene por objetivos la protección, la recuperación y el mejoramiento de los bosques nativos, con el fin de asegurar la sustentabilidad forestal y la política ambiental nacional.

37 Esta es una de las manifestaciones del principio de Independencia de los Tribunales de Justicia. Nuestra Constitución así lo establece en su artículo 76 al señalar el ámbito de funciones del Poder Judicial, cuando prohíbe a otros poderes toda injerencia en materias que están privativamente reservadas a él. Por su parte, el artículo 77 asegura esta independencia al establecer que la organización y atribuciones de los Tribunales de Justicia es materia de ley. Asimismo, esta idea la encontramos en el artículo 76 de la Constitución, donde se consagra la separación de poderes y la independencia de los tribunales. (Según Evans (2000), pp. 209-210; y Bordalí (2008), pp. 185219

38 "Artículo 60.- Cuando por unos mismos hechos y fundamentos jurídicos, el infractor pudiese ser sancionado con arreglo a esta ley y a otra u otras leyes, de las sanciones posibles, se le impondrá la de mayor gravedad. En ningún caso se podrá aplicar al infractor, por los mismos hechos y fundamentos jurídicos, dos o más sanciones administrativas." 
cuando examinen la investigación y las conclusiones del proceso sancionatorio. Así, se transformarían, sin serlo, en una especie de segunda instancia respecto de lo actuado por el organismo fiscalizador.

Lo anterior, coloca a este principio como un argumento adicional, en aras de la prevalencia de las obligaciones que pesan sobre CONAF de denunciar los incumplimientos a la ley forestal; de manera que, si pesa sobre los Directores Regionales la obligación de denunciar a la Justicia los incumplimientos señalados en las leyes en estudio, no puede un órgano de la Administración del Estado limitar o restringir el cumplimiento de dicha obligación. Una interpretación de esta naturaleza hace prevalecer las disposiciones de una ley simple frente a disposiciones del mismo rango, y dejaría en entredicho la facultad que tienen los Tribunales de Justicia para conocer oportuna y preferentemente de estos incumplimientos y tramitar las denuncias conforme a la ley.

Junto con ello, acceder a no denunciar las infracciones hasta que concluyan los procedimientos sancionatorios iniciados por la Superintendencia, haría incurrir a los Directores Regionales de CONAF en falta de servicio de notable abandono de deberes, debido a no cumplir en tiempo y forma lo que la ley establece en términos imperativos. Lo antes señalado se transforma en una interpretación que no resulta armónica con el resto de la legislación, máxime cuando el artículo 59 de la Ley Orgánica de la $\mathrm{SMA}^{39}$ no ampara la inactividad de los personeros antes mencionados en caso de que no cumplan con su mandato legal expreso.

\section{Conclusión}

El proceso de instalación de nuevas instituciones en la Administración del Estado, trae aparejadas diversas complicaciones cuando, por el silencio del legislador, se generan conflictos de facultades entre las de las instituciones antiguas existentes y aquellas que se le han conferido al nuevo organismo que entra en vigencia.

39 "Artículo 59.- Iniciado un procedimiento administrativo sancionador por parte de la Superintendencia no podrá ningún organismo sectorial con competencia ambiental, por los mismos hechos, iniciar un procedimiento administrativo sancionatorio de competencias propias o denunciarlos a la justicia civil, a menos que la Superintendencia se declare

${ }^{\mathrm{i}}$ ncompetente.

${ }^{\mathrm{L}}$ OS organismos sectoriales con competencia ambiental que, en el ejercicio de sus funciones, tomen conocimiento de estas infracciones estarán obligados a denunciarlos a la Superintendencia. En caso de que alguno de estos organismos iniciare un procedimiento respecto de materias que son competencia de la Superintendencia, ésta, de oficio o a petición de interesado, podrá solicitarle que se declare incompetente y le remita todos los antecedentes para iniciar el procedimiento respectivo". 
La problemática analizada, ha generado preocupación al interior de la CONAF, y es determinante para una armónica relación e interacción entre la institución encargada de la protección y regulación de -entre otras materias- el patrimonio forestal del país, y la institución encargada de velar por la correcta puesta en marcha y ejecución de los proyectos favorablemente calificados por el Servicio de Evaluación Ambiental, y el cumplimiento de las obligaciones contenidas en cada una de sus respectivas Resoluciones de Calificación Ambiental.

En el caso en análisis, se ha mostrado claramente la existencia de un conflicto de esta clase, que fácilmente pude confundirse con una "propietarización de facultades públicas" por parte de las instituciones preexistentes, pero que, en esencia, muestra un vacío que puede completarse mediante una interpretación jurídica por la vía de recurrir a la correspondencia y armonía de las normas entre sí, la historia fidedigna del establecimiento de las leyes en conflicto y, finalmente, la aplicación de criterios de especialidad, en el entendido de la competencia de cada una de las normas en el contexto en que rigen para determinar su real sentido y alcance.

No es menor la probabilidad de que esta misma problemática pueda existir en otros campos de la legislación sectorial, donde las infracciones que se constaten también deban denunciarse ante los Tribunales. Desde este punto de vista, lo aquí expuesto puede servir como un elemento más en análisis, que se ofrece como un aporte para la resolución de eventuales conflictos que al respecto se generen en el futuro.

\section{Referencias bibliográficas}

BASCUNAAN, Juan Francisco (2001). Jurisprudencia de la Contraloría General de la República relativa al Sistema de Evaluación de Impacto Ambiental: 1997-2000. COMISIÓN NACIONAL DEL MEDIO AMBIENTE CENTRO DE DERECHO AMBIENTAL UNIVERSIDAD DE CHILE. Edición de Marie Claude Plumer Bodin. Ed. Prograf. Santiago.

BOBBIO, Norberto (1999): “Teoría General del Derecho" En: LARA MÁRQUEZ, Jaime. Las antinomias en el Derecho: El caso de las leyes 29.214 y 29.215. En: Revista del Instituto Peruano de Derecho Tributario. [En línea] <http://www.ipdt.org/ editor/docs/01_Rev48_JLM.pdf> [consulta: 1 de junio de 2013]

BORDALÍ, Andrés (2008): "La doctrina de la separación de poderes y el poder judicial chileno”. [en línea]: Revista de Derecho de la Universidad Católica de Valparaíso XXX. Valparaíso, Chile. $1^{\circ}$ Semestre de 2008. Pág. 185-219. [Fecha de consulta: 5 de marzo 2013]. Disponible en: http://www.scielo.cl/scielo.php?script=sci_art text\&pid=SO718-68512008000100004)

CASTILLO GONZÁLEZ, Leonel (2010). Solución de conflictos de leyes. [En línea]: Cuarto Tribunal Colegiado en materia Civil del Primer Circuito. Tesis aisladas 
I.4‥C.220 C y I.4º.C.261 C en Resolución de Amparos Directos 293/2009 y 621/2009. [Fecha de consulta: 9 de agosto de 2012]. Disponible en: http://asadip. files.wordpress.com/2010/08/solucion-de-conflictos-de-leyes.pdf

CONGRESO NACIONAL DE LA REPÚBLICA DE CHILE (2010). Historia de la ley 20.417. Biblioteca del Congreso Nacional. Valparaíso, 2329 Pp. Pág. 474. CONGRESO NACIONAL DE LA REPÚBLICA DE CHILE. Boletín 9404-12. Valparaíso, 2012.97 Pp. [en línea]

$<$ http://www.senado.cl/appsenado/index.php?mo=tramitacion\&ac=getDocto\&idd octo=9819\&tipodoc=mensaje_mocion $>$ [consulta: 10 de septiembre de 2014].

COMISIÓN NACIONAL DEL MEDIO AMBIENTE, Región de Atacama (2007). [en línea]: Documento de Discusión. Proceso de Participación Ciudadana en la Generación de una nueva institucionalidad ambiental Para Chile. [Fecha de consulta: 10 de julio de 2013]. Disponible en: http://www.sinia.cl/1292/articles-40545_recurso_1.pdf

CORPORACIÓN NACIONAL FORESTAL Región de Coquimbo (2011), ORD No 49/2011, de 12 de Mayo de 2011.

ETCHEVERRY, Alfredo (1997). Derecho Penal, Parte General. Tercera Edición Revisada y Actualizada. Santiago, Chile. Editorial Jurídica de Chile. Tomo II, Santiago

GUZMÁN, Rodrigo (2012): Derecho Ambiental Chileno. Principios, instituciones, instrumentos de gestión. Chile. Editorial Planeta Sostenible. $1^{\circ}$ edición, Santiago, 268 Pp. Pág. 39.

SERVICIO DE EVALUACIÓN AMBIENTAL Región de Coquimbo (2011), ORD. $\mathrm{N}^{\circ} \mathrm{CE} / 536$, de 26 de Abril de 2011.

SERVICIO DE EVALUACIÓN AMBIENTAL Región de Coquimbo (2011), ORD. $\mathrm{N}^{\circ}$ CE/615, de 20 de Mayo de 2011.

SUPREMA CORTE DE JUSTICIA DE LA NACIÓN, México: El Principio de Non Bis in Idem. [En línea] [Fecha de consulta: 30 de enero de 2013]. Disponible en: http://www.scjn.gob.mx/Transparencia/Lists/Becarios/Attachments/10/ Becarios_010.pdf

\section{Normas Citadas}

Decreto Ley $\mathrm{N}^{\circ} 701$. Fija régimen legal de los terrenos forestales o preferentemente aptos para la forestación, y establece normas de fomento sobre la materia. Diario Oficial, 28 de octubre de 1974.

Ley $\mathrm{N}^{\circ}$ 19.300. Ley de bases del medio ambiente. Diario Oficial, 9 de marzo de 1994.

Ley N ${ }^{\circ}$ 20.283. Ley Sobre Recuperación del Bosque Nativo y Fomento Forestal. Diario Oficial, 30 de julio de 2008. 
Ley N ${ }^{\circ}$ 20.417. Crea el Ministerio, el Servicio de Evaluación Ambiental y la Superintendencia del Medio Ambiente. Diario Oficial, 26 de enero de 2010.

Decreto 95/2001 MINSEGPRES. Modifica Reglamento del Sistema de Evaluación de Impacto Ambiental. Diario Oficial, 7 de diciembre de 2002.

Decreto 40/2012 MMA. Aprueba reglamento del Sistema de Evaluación de Impacto Ambiental. Diario Oficial, 12 de agosto de 2013

\section{Jurisprudencia Citada}

Sentencia del Tribunal Constitucional de Chile, 6 de enero de 2010, autos rol No 1554-09-CPR, en: Diario Oficial, 26 de enero de 2010, Ley N²0.417.

\section{Abreviaciones usadas:}

CONAF

D.L.

Hon.

LOSMA

MINSEGPRES

MMA

ORD.

Pág.

PAS

Pp.

RCA

SEA

SEIA

SMA
Corporación Nacional Forestal.

Decreto Ley.

Honorable.

Ley Orgánica de la Superintendencia del Medio Ambiente.

Ministerio Secretaría General de la Presidencia.

Ministerio del Medio Ambiente.

Ordinario (Oficio Ordinario).

Página.

Permiso Ambiental Sectorial.

Páginas.

Resolución de Calificación Ambiental.

Servicio de Evaluación Ambiental.

Sistema de Evaluación de Impacto Ambiental.

Superintendencia del Medio Ambiente. 